\title{
Sebaceous Filaments
}

\author{
Yuvrah Singh ${ }^{1}$, Shekhar Neema ${ }^{1}$, Amit Bahuguna ${ }^{1}$, Disha Dabbas ${ }^{1}$
}

1 Department of Dermatology, Armed Forces Medical College, Pune, India

Key words: sebaceous filaments, Demodex, mites, dermoscopy

Citation: Singh Y, Neema S, Bahuguna A, Dabbas D. Sebaceous filaments. Dermatol Pract Concept. 2021;11(1):e2021148. DOI: https://doi.org/10.5826/dpc.1101a148

Accepted: August 17, 2021; Published: January 29, 2021

Copyright: (O2021 Singh et al. This is an open-access article distributed under the terms of the Creative Commons Attribution License BYNC-4.0, which permits unrestricted noncommercial use, distribution, and reproduction in any medium, provided the original author and source are credited.

Funding: None.

Competing interests: The authors have no conflicts of interest to disclose.

Authorship: All authors have contributed significantly to this publication.

Corresponding author: Shekhar Neema, MD, Department of Dermatology, Armed Forces Medical College, Pune, Maharashtra, India. Email: shekharadvait@gmail.com

\section{Case Presentation}

A 16-year-old boy with a known case of autism spectrum disorder presented with complaints of multiple yellowish white deposits over hair-bearing areas of his face for the previous 3 years. On examination, there were multiple filamentous, off-white to yellowish, follicular growths in his perioral region, eyelashes, eyebrows, nose, and cheeks (Figure 1A). Dermoscopy revealed uniform cylindrical, solid, off-white colored deposits encircling normal hair follicles (Figure 1B). The gram stain and potassium hydroxide preparations were negative. The growths were clinically diagnosed to be sebaceous filaments.
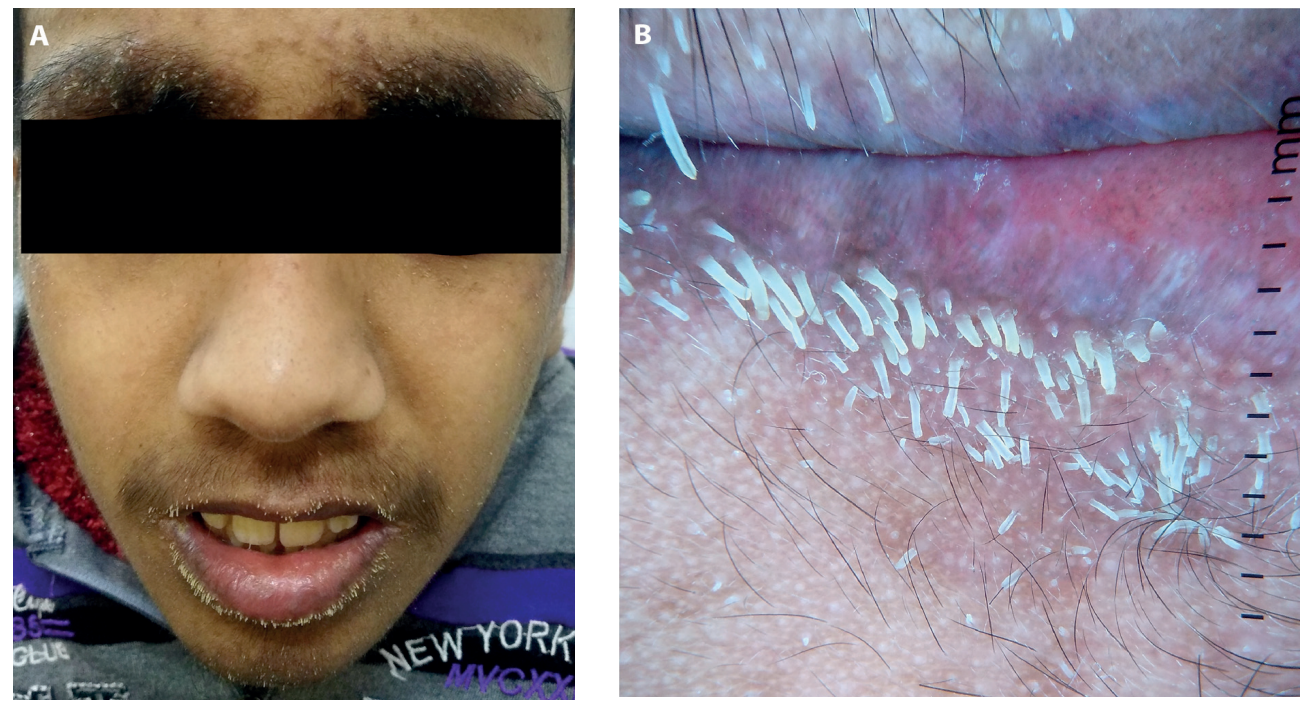

Figure 1. (A) Filamentous, off-white to yellowish follicular growths in the perioral region, eyelashes, eyebrows, nose, and cheeks. (B) Uniform, cylindrical, solid, off-white colored deposits encircling normal hair follicles seen on non-polarized dermoscopy. 